\title{
New species of egg parasites from the Oil Palm Stick Insect (Eurycantha insularis) in Papua New Guinea (Hymenoptera, Chrysididae, Phasmatodea, Phasmatidae)
}

\author{
Lynn S. Kimsey ${ }^{1, \dagger}$, Charles F. Dewhurst ${ }^{2, \ddagger}$, Seno Nyaure ${ }^{2, \S}$
}

I Bohart Museum of Entomology, Department of Entomology, University of California, One Shields Ave., Davis, California 95616, USA 2 Papua New Guinea Oil Palm Research Association Inc., Dami Research Station, Kimbe, West New Britain, Papua New Guinea

† urn:lsid:zoobank.org:author:ADC91A84-7D87-41E4-A4B3-87BA1041D7DD

¥urn:lsid:zoobank.org:author:579B5A2F-7745-413F-B647-CA93B27A206F

§ urn:lsid:zoobank.org:author:335C5132-FC9A-468C-AED9-E71D0E780A37

Corresponding author: Lynn S. Kimsey (lskimsey@ucdavis.edu)

Academic editor: W. Pulawski | Received 19 September 2012 | Accepted 27 November2012 | Published 30 January 2013

urn:lsid:zoobank.org:pub:9FDF6BOC-DF10-4777-A29C-3725F7E6E0DD

Citation: Kimsey LS, Dewhurst CF, Nyaure S (2013) New species of egg parasites from the Oil Palm Stick Insect (Eurycantha insularis) in Papua New Guinea (Hymenoptera, Chrysididae, Phasmatodea, Phasmatidae). Journal of Hymenoptera Research 30: 19-28. doi: 10.3897/JHR.30.4010

\begin{abstract}
Two new species of amisegine chrysidids, Cladobethylus insularis and Exova tunana, are described. Both species were reared from eggs of the stick insect, Eurycantha insularis Lucas (Phasmatidae), collected from infestations of oil palm pests in Papua New Guinea. This is the first host record for either genus.
\end{abstract}

\section{Keywords}

Cladobethylus, Exova

\section{Introduction}

Outbreaks of the oil palm stick insect, Eurycantha insularis Lucas, 1869 (Figs 1, 2), occurred in 2007 and 2008 in smallholder oil palm plantations in the Tunana smallholder blocks in Northern (Oro) Province, Papua New Guinea. Damage caused by these stick

Copyright Lynn S. Kimsey et al. This is an open access article distributed under the terms of the Creative Commons Attribution License 3.0 (CC-BY), which permits unrestricted use, distribution, and reproduction in any medium, provided the original author and source are credited. 


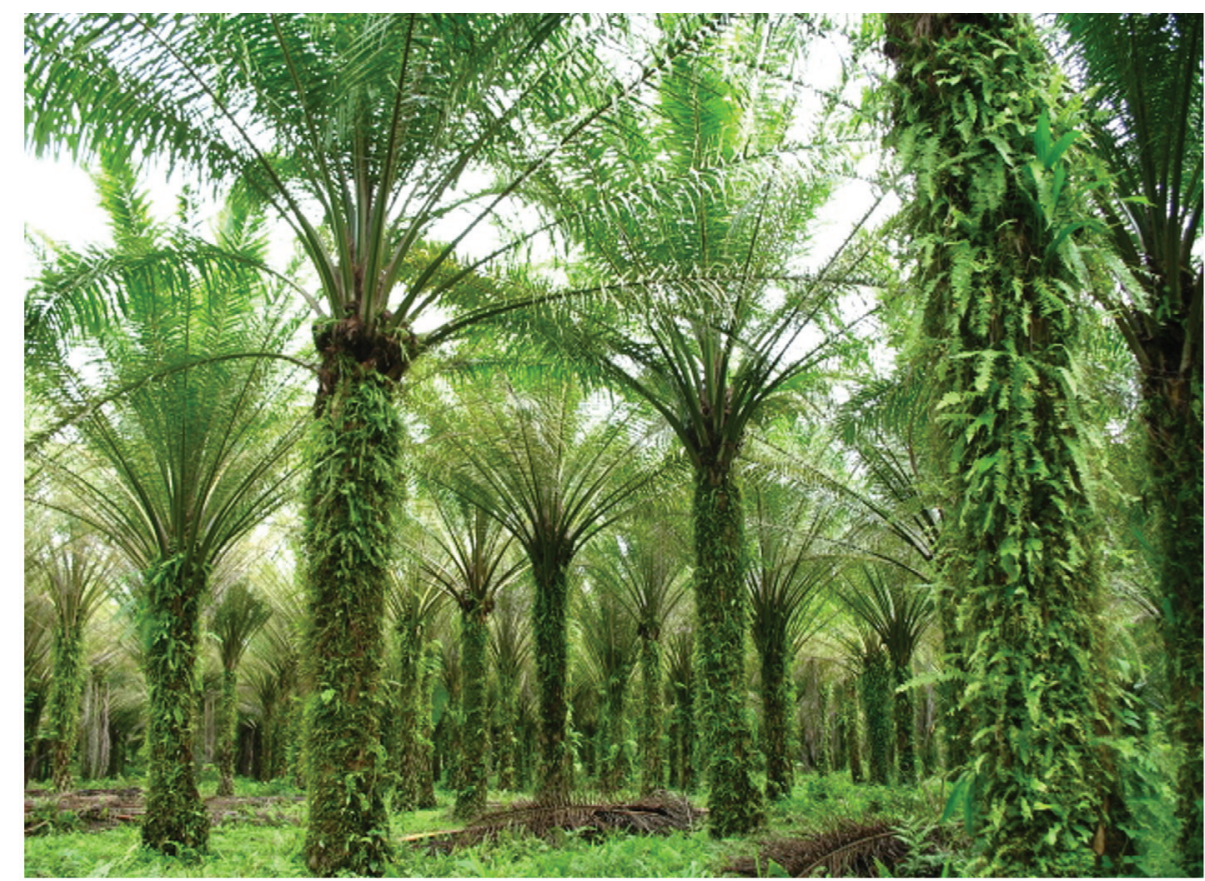

1.
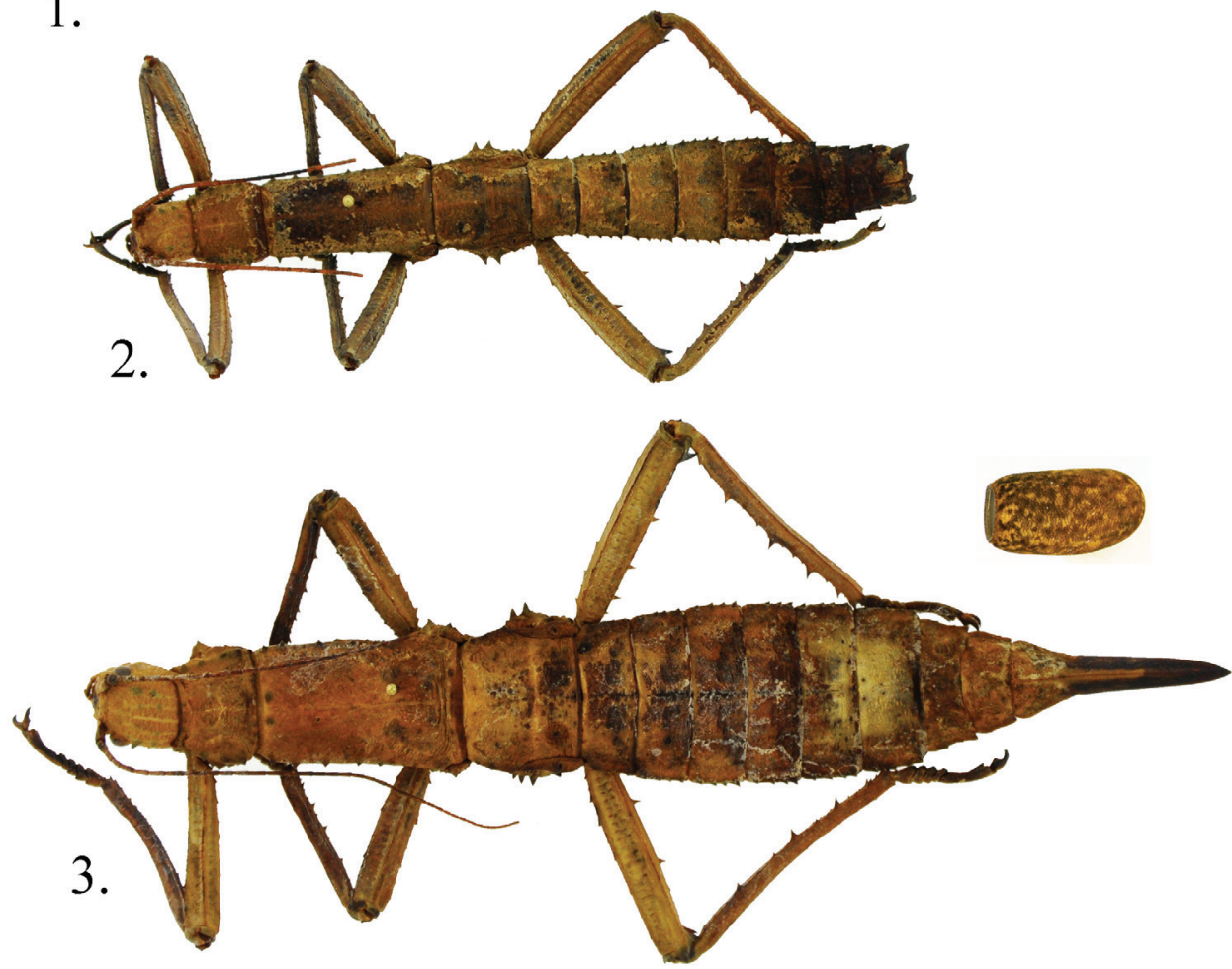

Figures I-3. Eurycantha insularis Lucas I feeding damage in Tunana small holding oil palm plantation in Papua New Guinea 2 Male 3 Female with parasitized egg; egg not to scale. 
insects can be seen in Fig. 3. Eggs from this stick insect were regularly collected during these infestations and two new species of chrysidid egg parasites, Exova tunana sp. n. and Cladobethylus insularis sp. n. described below were reared from the eggs. There is no information on the ecology of these parasitoids except for the rearing information.

There are seven named species of Cladobethylus and two species of Exova described prior to those described below (Kimsey and Bohart 1991, Kimsey 2011). The new species of Cladobethylus described below is the second one recorded from New Guinea. Exova is known from northern Australia and Fiji, so it is not surprising to find a species in Papua New Guinea.

\section{Materials and methods}

Specimens were all reared by the second and third authors and their staff at PNGOPRA, Higaturu Centre, Northern Province, Papua New Guinea.

Types are deposited in the following museums and institutions: CANBERRA Australian National Insect Collection, CSIRO, Canberra, ACT, Australia; DAVIS Bohart Museum of Entomology, University of California, Davis, USA; KIMBE - Papua new Guinea, PNG Oil Palm Research Association Dami Research Station, Kimbe, West New Britain Province; LONDON - The Natural History Museum, London, England, and PORT MORESBY - the National Insect Collection, Port Moresby, Papua New Guinea.

\section{Cladobethylus insularis Kimsey \& Dewhurst, sp. n.}

urn:1sid:zoobank.org:act:B4B4A207-A0D8-43E8-87D2-1E76C0F155E0 http://species-id.net/wiki/Cladobethylus_insularis

Figs 4-10

Holotype male. Papua New Guinea, Northern (Oro) Province, Higaturu, ex Eurycantha insularis egg, second generation coll. 23/ii/2009, died 23/ii/2009 C. F. Dewhurst, No. 888 (LONDON).

Paratypes (17 males, 3 females): same data as holotype except: 1 male, $1^{\text {st }}$ generation, em. (emerged) 28/xii/2008, died 5/i/2009, C. F. Dewhurst, No. 855; 1 male, $1^{\text {st }}$ generation, emerged 28/xii/2008, died 5/i/2009, S. Nyaure, No. 855; 1 female, $1^{\text {st }}$ generation, emerged 8/ii/2008, died 14/ii/2008, C. F. Dewhurst, No. 833; 1 male, $1^{\text {st }}$ generation, emerged 6/i/2009, died 17/i/2009, S. Nyaure, No. 869; 1 male, $1^{\text {st }}$ generation, emerged $2 / \mathrm{i} / 2009$, died 9/i/2009, S. Nyaure, No. 862; 1 male, $1^{\text {st }}$ generation, emerged $\&$ dead 22, 23, 25/i/2009, S. Nyaure, No. 875; 1 male, $2^{\text {nd }}$ generation, coll. 3/ii/2009, died 16/ii/2009, C. F. Dewhurst, No. 887; 1 male, Higaturu Oil Palms, coll. 8/v/2007, H9/vi/2007, C. F. Dewhurst, Nos. 823; 3 males, $2^{\text {nd }}$ generation, coll. 25/vii/2009, died 27/vii/2009, C. F. Dewhurst, No. 893, 894, 895; 1 male, $2^{\text {nd }}$ generation, coll. 5/ii/2009, died 20/ii/2009, C. F. Dewhurst, No. 890; 1 male, 1 female, 


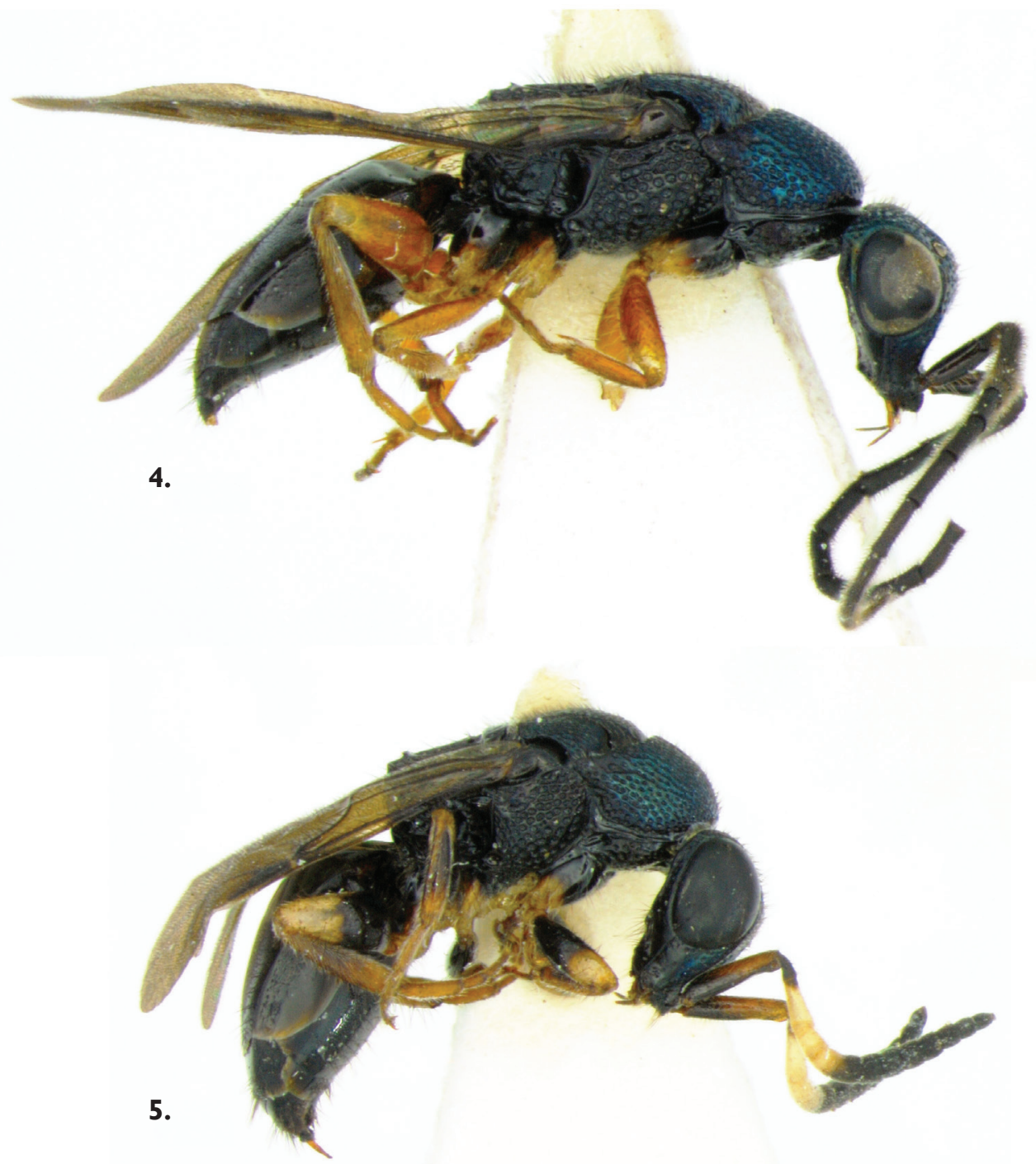

Figures 4-5. Cladobethylus insularis, side views 4 Male 5 Female.

$2^{\text {nd }}$ generation, coll. $26 / \mathrm{i} / 2009$, died 16/ii/2009, C. F. Dewhurst, No. 881, 882; 1 male; $2^{\text {nd }}$ generation, coll. 8/ii/2009, died 16/ii/2009, C. F. Dewhurst, No. 8923; 1 male, $2^{\text {nd }}$ generation, coll. 2/ii/2009, died 15/ii/2009, C. F. Dewhurst, No. 886; 1 male, emerged $12 / \mathrm{ii} / 2008$, died $17 / \mathrm{ii} / 2008$, C. F. Dewhurst, No. 837; 1 female, $2^{\text {nd }}$ generation, coll. 27/i/2009, died 21/ii/2009, C. F. Dewhurst, No. 883 (CANBERRA, LONDON, DAVIS, KIMBE, PORT MORESBY).

Diagnosis. This is the largest bodied species of Cladobethylus, with males averaging twice the length of the known other species. Male insularis can be distinguished from aquilus, the only other species known from New Guinea by the longer malar 


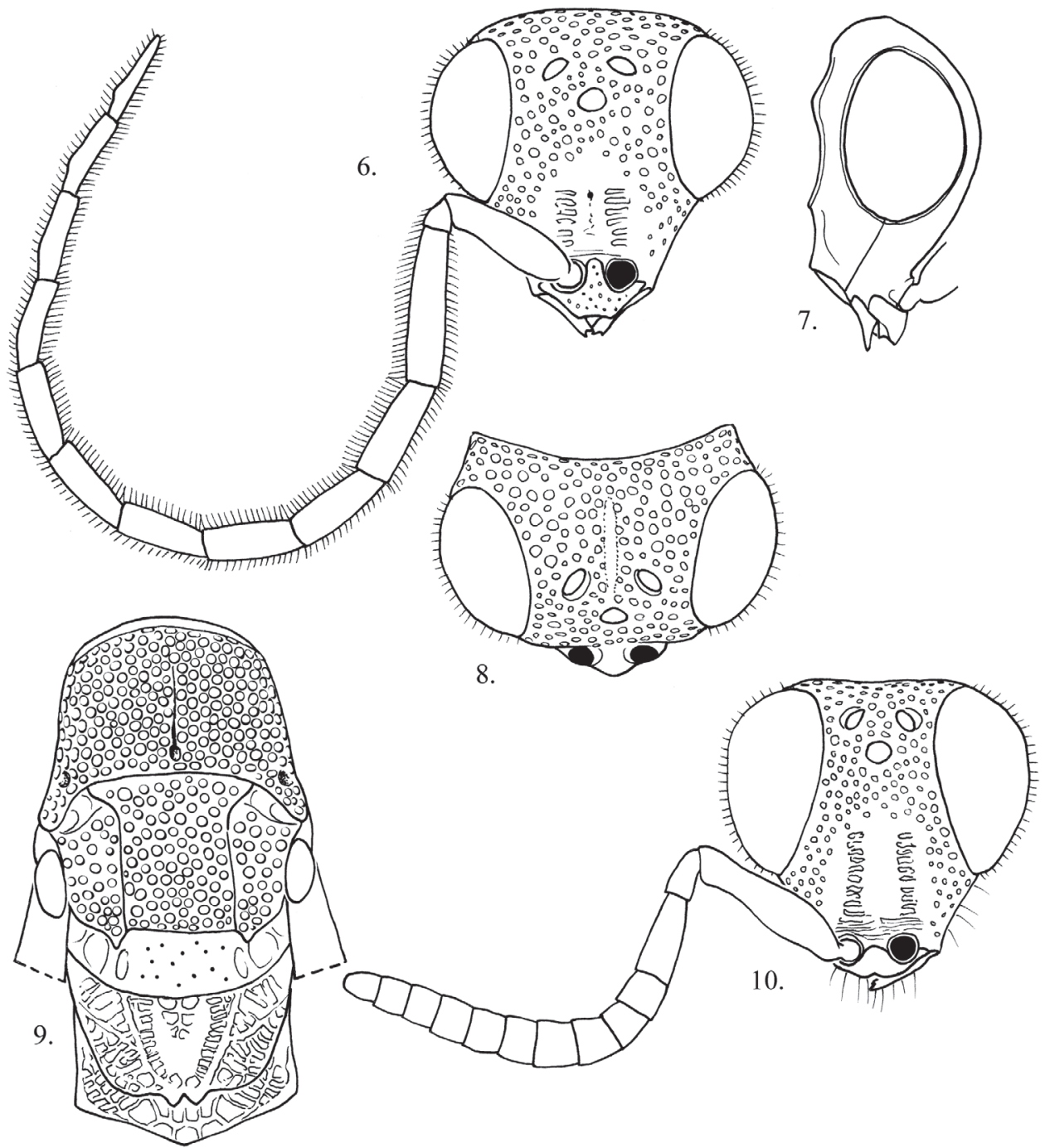

Figures 6-10. Cladobethylus insularis 6-8 Male head 6 Front view 7 Lateral view 8 Dorsal view 9 Dorsal view of male mesosoma, wings removed 10 Front view of female face.

space (4 midocellus diameters versus 3.5 in aquilus), pronotum not blue-tinted, much broader zone of cross-ridging in the scapal basin, legs brown instead of yellow (aquilus) flagellomere I shorter ( $4.5 \times$ as long as broad versus $5 \times$ in aquilus) and flagellomere $\mathrm{XI}$ shorter $(5 \times$ as long as broad versus $6 \times$ in aquilus). Features of female insularis not shared with other Cladobethylus include the bicolored antenna and legs, long clypeus (0.8 midocellus diameter long versus $0.3-0.6$ midocellus diameters in other species), and narrow distance between the midocellus and nearest eye margin (up to 2 midocellus diameters versus 2.6-2.7 midocellus diameters in the others).

Description. Male (Fig. 4). Body length. 5-7 mm. 
Head (Figs 6-8). Face about as long as broad across the eyes; genal area without foveae; midocellus 1.8 diameters from ocular margin; hindocelli 4 diameters from posterior margin of vertex; scapal basin with narrow, longitudinal submedial band of cross-ridges; malar space 3.5-3.8 midocellus diameters; subantennal distance 1 midocellus diameter long; flagellomere I $4 \times$ as long as broad; flagellomere II $2.8-3.0 \times$ as long as broad; flagellomere IX $5 \times$ as long as broad, flagellar setae 0.7 midocellar diameter long; ocular setulae 0.4 midocellus diameter long.

Mesosoma (Fig. 9). Pronotum about as long as scutum; punctation on pronotum, scutum and mesopleuron large, deep and nearly contiguous punctuation, without scrobal sulcus or omaulus; scutellum polished with scattered tiny punctures; metapleuron polished, impunctate.

Metasoma. Tergum I polished with few tiny highly scattered punctures; tergum II with two large ovoid patches of small punctures, 1 puncture diameter apart, separated medially by impunctate band and with broad apical impunctate band; terga III-IV with tiny punctures 1 puncture diameter apart, becoming sparser toward apical margin.

Color. Head, meso- and metasoma black with metallic bluish green highlights dorsally on head, pronotum and scutellum, sometimes faint on metasomal terga; mandible and antenna dark brown; legs light reddish brown, except coxae dark brown to black basally; wing membrane brown-tinted, darkest in vicinity of stigma; wing veins dark brown.

Female (Fig. 5). Body length. 4.5-5.5 mm. As in the male, except face (Fig. 10) about as long as broad across the eyes; malar space 3.6-3.8midocellus diameters; subantennal distance 0.8 midocellus diameter; flagellomere I $2.4 \times$ as long as broad; flagellomere II long as broad; flagellomere IX 1.3× as long as broad; scape, pedicel black, flagellomeres I-III white, remaining flagellomeres black; coxae, femora, mid and hindtibiae black basally, whitish apically; foretibia and tarsi brown; wing membrane brown-tinted with dark brown veins.

Etymology. The species is named after the host species.

\section{Exova tunana Kimsey \& Dewhurst, sp. $\mathbf{n}$.}

urn:lsid:zoobank.org:act:74C249EB-0312-4710-A9E1-178BEA990A75

http://species-id.net/wiki/Exova_tunana

Figs $11-18$

Holotype male. Papua New Guinea, Northern (Oro) Province, Saiho Division (Tunana), ex Eurycantha insularis egg, emerged 27/vii/2007, died 30/vii/2007, C. F. Dewhurst, No. 828 (LONDON).

Paratypes: 1 male, emerged 5/ii/2008, died 13/ii/2008, C. F. Dewhurst, No. 831; 1 female, emerged 10/ii/2008, died 15/ii/2008, C. F. Dewhurst, No. 835; 1 female, Higaturu, $1^{\text {st }}$ generation, coll. 2/vi/2008, died 12/vi/2008, C. F. Dewhurst, No. 841 (CANBERRA, DAVIS, KIMBE, PORT MORESBY).

Diagnosis. This is the largest bodied species of Exova. Female tunana can be distinguished from fijiensis Kimsey by the long spine-like propodeal angle (a feature shared 


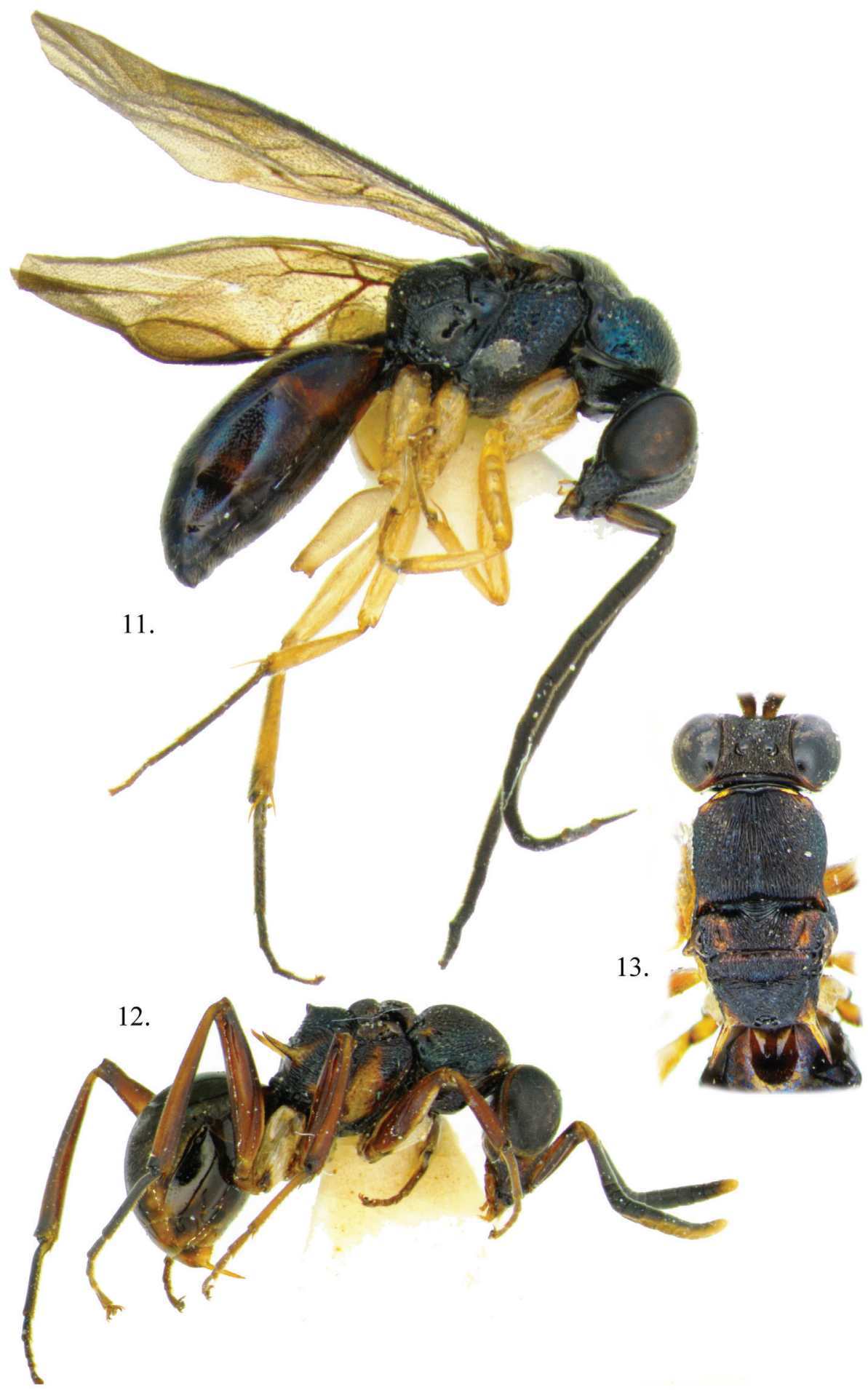

Figures II-|3. Exova tunana, side views II Male I 2 Female $\mathbf{3}$ Dorsal view of female Mesosoma. 


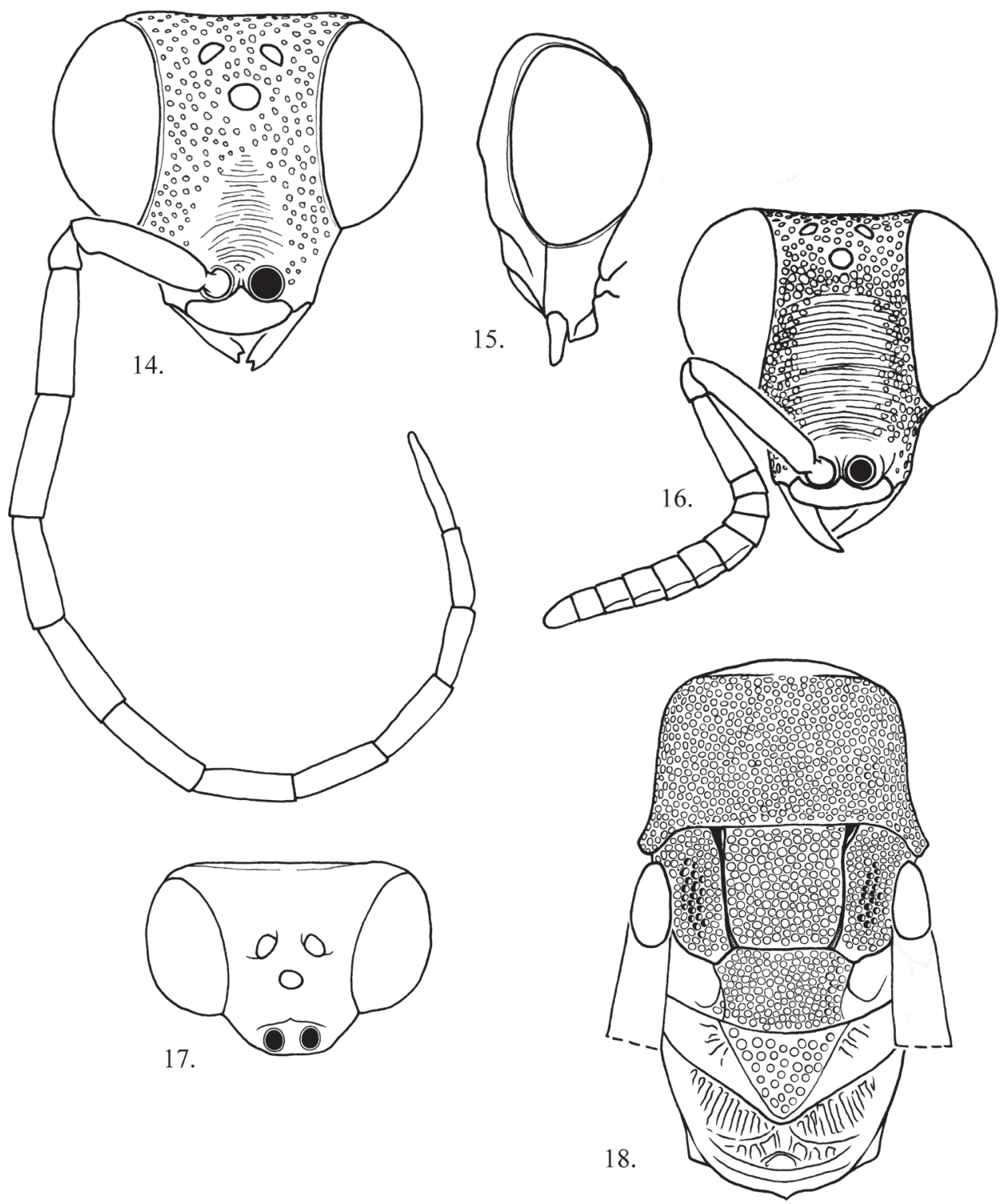

Figures 14-18. Exova tunana 14, 15, I8 Male head I4 Front view I5 Lateral view I 8 Dorsal view 16 Female head front view. 17 Dorsal view of male mesosoma, wings removed.

with tetraspina), which is conical in fijiensis. Female fijiensis can be distinguished from tetraspina by the more weakly produced medial propodeal projections and the highly polished and smooth metapleuron and propodeum. Male tunana can be distinguished from fijiensis by the shorter distance from the midocellus to ocular margin (2 midocellus diameters or less in tunana versus 2.5 midocellus diameters in fijiensis), flagel- 
lomeres I and II equivalent versus I much longer than broad than II in fijiensis and the body with bluish green tints versus brassy in fijiensis.

Description. Male (Fig. 11). Body length. 5.0-5.5 mm.

Head (Figs 14, 15, 17). Face 1.0-1.2 $\times$ as long as broad across the eyes; face between scapal basin and vertex with punctures separated by about 1 puncture diameter; scapal basin with cross-ridged medial zone occupying one-third of area between inner eye margins; midocellus 1.9 diameter from ocular margin; malar space 2.5 midocellus diameters; subantennal distance 1 midocellus diameter long; flagellomeres I-II 3.5-3.6x as long as broad; flagellomere IX 6x as long as broad; flagellar setae short, 0.1 midocellus diameter long; ocular setulae minute or absent; postocular distance 0.4 midocellus diameter wide.

Mesosoma (Fig. 18). Pronotum about as long as scutum; mesopleural punctures nearly contiguous, without scrobal sulcus or omaulus; metapleuron horizontally crossridged.

Metasoma. Tergum I polished, nearly impunctate with scattered tiny punctures; terga II-IV with small punctures separated by 2-3 puncture diameters.

Color. Head, meso- and metasoma black with metallic bluish green tints dorsally; antenna black, legs pale yellow; wing membrane brown-tinted, veins dark brown.

Female (Fig. 12). Body length. 6-7 mm.

Head (Fig. 16). Face $0.9 \times$ as long as broad across the eyes in front view; scapal basin with medial one-half to one-third coarsely transversely striate, laterally with dense contiguous punctures; malar space 4.3 midocellus diameters; subantennal distance 1 midocellus diameter; flagellum fusiform, broadest medially, flattened ventrally; flagellomere I $2.8 \times$ as long as broad; flagellomere II $0.7 \times$ as long as broad; flagellomere IX $1.2 \times$ as long as broad.

Mesosoma (Fig. 13). Apterous; pronotum and scutum densely longitudinally striate, pronotum $0.7 \times$ as broad as long, $1.4 \times$ as long as length of scutum plus scutellum; scutellum transversely striate.

Metasoma. Polished; tergum I with fine dense scratches in two touching posteromedial patches, scratches parallel and curving laterally; tergum II with two anteromedial patches of dense curved scratches subtended by large medial patch of dense posteriorly curved fine scratches; terga III and IV smooth with scattered tiny punctures.

Color. Body dark reddish brown, paler on side of scapal basin, mesopleuron medially, propodeal spines, legs and metasomal apex; apical flagellar segments yellowish beneath; coxae whitish.

Etymology. The species is named after the collection site in Northern Province, PNG.

\section{Acknowledgements}

This study was made possible by the efforts of Entomology Section staff at the PNGOPRA Higaturu Research Centre, Northern Province. CFD acknowledges The Director of Research, PNGOPRA for permission to publish this article. 


\section{References}

Kimsey LS (2011) Re-examination of the genus Exova Riek, with the first chrysidid recorded from Fiji (Hymenoptera: Chrysididae: Amiseginae). Proceedings of the Entomological Society of Washington 113(4):436-441. doi: 10.4289/0013-8797.113.4.436

Kimsey LS, Bohart RM (1991 [1990]) Chrysidid Wasps of the World. Oxford University Press $651 \mathrm{pp}$. 